\title{
Research on the Influencing Factors and Mechanism to Innovation Performance of Team Psychological Empowerment
}

\author{
Caihong Zhang, Canqiu Zhong \\ Management School, Jinan University, Guangzhou, China \\ Email: zhangcaihong@aliyun.com, zcq199011@foxmail.com
}

Received 2 November 2014; revised 1 December 2014; accepted 8 December 2014

Copyright (C) 2014 by authors and Scientific Research Publishing Inc.

This work is licensed under the Creative Commons Attribution International License (CC BY). http://creativecommons.org/licenses/by/4.0/

(c) (7) Open Access

\begin{abstract}
Team psychological empowerment refers to the collective cognition which team members emerge from the state that how their teams have been empowered. More empowered teams tend to perform better than the less empowered teams, especially on the innovation behavior and creative outcome. This paper presents the connotation and measurement methods of team psychological empowerment, and then summarizes and discusses the influencing factors and mechanism to innovation performance of organizations. Finally, a brief outlook for the future research has been conducted.
\end{abstract}

Keywords

Team Psychological Empowerment, Connotation, Innovation Performance, Creativity

\section{Introduction}

Creative talents play the key role in the industry reform and upgrading, and psychological empowerment, which is considered as the inherent motivation that can drive the creativity and innovational behavior of employees, will cultivate the needed creative talents in companies effectively. Therefore, how to improve the perception of psychological empowerment of crucial employees has attracted wide concern in the academic and enterprise field. Numerous studies suggest that psychological empowerment has significant impact on the innovation and performance of organizations [1]-[4], customer service level and employees' satisfaction [5]. High psychologically empowered teams tend to outcome better innovation performance than the low psychologically empowered teams, especially in higher organization innovation climate and creative ability [6]-[9].

The aim of the paper is to sort out the connotation, dimension and measurement methods of team psychologi- 
cal empowerment, then examine and conclude the influencing factors and mechanism to innovation performance of team psychological empowerment; finally, a brief outlook for the future research has been conducted.

\section{The Connotation and Dimension of Team Psychological Empowerment}

Empowerment originates from the separation of powers that managers delegate to their subordinates. This means that leaders empower rights to the employees by delegating the decision-making power, implementing job enrichment and transforming more available and helpful information and resources to the gross root employees. The prior study mainly focused on the leadership behavior of managers who empower to subordinates. Gradually, with further research in empowerment, scholars started to concern the perception of empowerment in the employees, thus the concept of psychological empowerment appeared. Thomas \& Velthouse (1990) believed that individual psychological empowerment as the intrinsic task motivation, which was motivated by the superiors to the self-efficiency of the subordinates, could reduce the sense of non-power from the subordinates and improve their performance. Besides, individual psychological empowerment was not the single dimensional concept that people perceived previously, but was a model that was made up of four multi-dimensional aspects, including impact, competence, meaning and self-determination. Impact is the degree to which an individual can influence strategic, administrative, or operating outcomes at work. Competence is an individual's belief in his or her capability to perform activities with skill. Meaning is the value of a work goal or purpose, judged in relation to an individual's own ideals or standards. Self-determination is an individual's sense of having choices in initiating and regulating actions [3] [10].

With extensive studies of individual psychological empowerment, team psychological empowerment has drawn public attention. Comparing with the individual psychological empowerment that only focuses on the self-empowered degree, Kirkman \& Rosen (1997) argued that team psychological empowerment was the collective cognition that team members respond to their stay environment [6]. The connotation of team psychological empowerment mainly has two perspectives: two-dimension perspective and four-dimension perspective.

The two-dimension perspective suggests that team psychological empowerment involves empowered authority and related responsibility. Superiors will distribute work tasks to the teams that have self-determination, and the teams should take related responsibility collectively, accepting the decision outcomes and solving their own problems [11]-[13]. This structure mainly laid emphasis on two aspects: delegated power and team responsibility.

The four-dimension perspective is the extension of individual psychological empowerment proposed by Thomas \& Velthouse (1990). Like individual psychological empowerment, team psychological empowerment includes four aspects as well: team potency, team meaningfulness, team autonomy and team impact. These dimensions are not only related to each other, but also different from each other. The four-dimension perspective is more micro and focuses on the sense of psychology and perception of empowered employees.

The above two definitions of team psychological empowerment both emphasize team autonomy and collective perception, but Kirkman's concept is more completed and spercific. Except for the collective perceived cognition level, it also involves the importance of team tasks and team impact. Therefore, the four-dimension perspective has higher recognition, and most studies adopt this connotation in their papers [14]-[16].

\section{The Measurement of Team Psychological Empowerment}

The earliest team psychological empowerment scale was developed by Kirkman \& Rosen (1999). The scale included four dimensions: team potency, team meaningfulness, team autonomy and team impact. Team potency is the collective belief of a team that it can be effective; Team meaningfulness refers to a team's experiencing its tasks as important, valuable and worthwhile. Team autonomy is the degree to which team members experience substantial freedom, independence and discretion in their work. Team impact means a team produces work that is significant and important for an organization. There are 26 items in this scale, and the factor analysis suggests that all these four dimensions have high factor loads, which can account for $92 \%$ variance. The Cronbach's $\alpha$ of the whole scale reaches to 0.96 [7]. Afterwards, the scale was adopted by scholar Kirkman \& Shapiro (2001) [17], Proenca (2007) [18] and so on.

Since several items in each dimension of this team psychological empowerment scale have high correlation [17], Kirkman et al. (2004) shorten the original scale to become more briefly and apply in more contexts, from 26 items to 12 items. The abbreviated scale suggests that it has better convergent validity and discriminant validity through analysis of variance and examination of ICC. The Cronbach's $\alpha$ of the whole scale is 0.93 [8]. 
Afterwards, Somech (2005) [19], Chen et al. (2007) [14] and Zhang \& Begely (2011) [20] applied this abbreviated team psychological empowerment scale in their research.

As the psychological empowerment study boomed in china, Wang et al. (2012) developed team psychological empowerment in Chinese context. His research combined the methods of open-ended questionnaire survey, structure interview, explorative and confirmative factor analysis, and discovered that Chinese team psychological empowerment scale was two-dimension structure-task-oriented empowered experience and competenceoriented experience. Apart from the four dimensions of team psychological empowerment in western study, he argued that competence-oriented experience of team psychological empowerment in Chinese context referred to job skills, problem solving, knowledge acquirement and knowledge application, while the task-oriented empowered experience also included the extent that team members concerned their team tasks. It is suggested that the scale has high structure validity, criterion related validity, content validity and discriminative validity as well as good reliability, with as much as 0.903 Cronbach $\alpha$ [21].

\section{The Influencing Factors of Team Psychological Empowerment}

The literature study discovers that the influencing factors of team psychological empowerment can be classified two characters-team external character and team internal character. The team external character involves external team leader behavior, organization character and national culture, while the team internal character involves job task character and team character.

\subsection{Team External Character}

According to the definition by Kirkman \& Rosen (1997), external team leader behavior refers to the leaders or managers out of teams empowering team autonomy, asking for advice repeatedly when making organization decision and enhancing team members' individual sense of perceived control. This study chose 112 teams from four formal organizations that had set up work teams as samples, and the structural equation analysis indicated that external team leadership behavior and team-based human resources policies were positively related to team psychological empowerment [7]. Besides, Seibert's et al. (2011) [16] meta-analysis and Mathieu's et al. (2006) [12] and Chen's et al. (2007) [14] studies also proved that both high performance management practice and positive leadership have positive impact on team psychological empowerment. Clearly, the high performance practice means that organization leaders share more information with teams, delegate authority to teams, encourage team members to participate in group decision-making, conduct related training and set up team compensation [16].

Organizational factor is another significant team external character of team psychological empowerment. Empirical studies by Kirkman \& Rosen (1997) have shown that organization social structure support (For instance, have access to strategic information and work unit resources, have a high degree of inter-team coordination and communication, provide team members with materials and supportive resources) is positively related to team psychological empowerment [7]. On the other hand, organizational structure type has a close relationship with team psychological empowerment. The most two crucial organizational structure are decentralization and formalization, specifically, decentralization describes the extent to which power or authority is either concentrated or shared, while formalization relates to the use of explicit rules, policies and procedures. Hempel et al. (2012) used teams drawn from 94 Chinese high-technology companies and conducted the feasibility of team psychological empowerment in Chinese context. The results showed that when organizations had high decentralization level, even if decision making was delegated downward or not directly delegated to teams, team psychological empowerment would enhance accordingly. Furthermore, the study also proved that team psychological empowerment would enhance, as organizational level to which formalization is applied improved. However, formalization of jobs and roles would reduce the sense of team psychological empowerment, because if formalization that applies within the team by specifying job roles of individual team members will act to constrain the team's freedom of action within the boundaries of the team , and thus hindering the development of team psychological empowerment [15].

Apart from that, national culture is also a key factor that will restrain team psychological empowerment. Plenty of studies have proved that China is a high power-distance, low empowerment and high team cooperation society. Zhang \& Begley (2011) found that team psychological empowerment and team cooperation had no relationship in Chinese high power-distance organization, whereas team psychological empowerment was positively 
related to team cooperation in low power-distance organization context. This means that high power-distance organization will hinder the perception of team psychological empowerment, while low power-distance organization will promote the awareness of team psychological empowerment and team cooperative actions [20].

\subsection{Team Internal Character}

Quite a few studies indicated that task characteristics have positive relation with team psychological empowerment [16] [22]. For instance, production/service responsibilities, which contain setting their own production or service goals, making important decisions such as scheduling and production/service assignments, monitoring and training for quality, handling customer issues and complaints, are common in most organizations. Moreover, when distributing bigger challenging and more important job tasks to teams, team members will increase the sense of meaningfulness of team tasks purposely and perceive more empowerment to make effort to work harder to fulfill goals. But Mathieu et al. (2006) believed that there was no evident relationship between task characteristics and team psychological empowerment [12]. This was mainly because the connotation of team psychological empowerment in this study was previously discussed two-dimension structure, which focused on delegation and responsibility, but excluded the content of job meaning and content of job characteristics, leading the insignificant relationship conclusion between these two variables.

Chen et al. (2007) found that team interdependence presented a vital role in influencing different team empowerment levels. When there was more interaction between team members (high interdependence), the degree of team psychological empowerment would increase as well. In contrast, low interdependent team tended to have low degree of team psychological empowerment. Besides, Kirkman \& Shapiro (2001) conducted empirical study of team internal characters in self-management work teams and found that team assistance is negatively related to team psychological empowerment [17].

\section{Mechanism to Innovation Performance of Team Psychological Empowerment}

Existed empirical studies suggested that team psychological empowerment showed different influencing degree to innovation performance in individual level, team level and organizational levels.

Work teams are the most common teams in companies or organizations. Kirkman \& Rosen (1997) studied this kind of teams and suggested that high psychological empowered teams tended to perform higher individual work initiatives and job satisfaction. To be more exactly, when the team has high team psychological empowerment, it will achieve their team's goal with high self-determination, therefore, members in this team will experience high satisfaction and productivity as well [6]. For the study of nursing teams in medical organizations, it is indicated that team psychological empowerment act as the role of mediator in the relationship that team context and team atmosphere have positive impact on employees' job satisfaction [18]. On the other hand, teams for the need of teaching and scientific research that depend on mutual resources and knowledge to fulfill jobs are more complicated in terms of team psychological empowerment toward individual performance. Somech (2005) chose more than 2400 teachers in different schools and conducted the multi-level study of psychological empowerment between individual level and team level. The results showed that the interaction between individual psychological empowerment and team psychological empowerment determines the degree of teachers' professional commitment. Only when individual psychological empowerment is high and team psychological empowerment is low or individual psychological empowerment is low and team psychological empowerment is high, will teachers' professional commitment improve. What's more, if teachers' professional commitment is higher, individual performance can be more satisfied [19].

Most of the consequences between team psychological empowerment and team performance conduct by mediating variables. Mathieu et al. (2006) pointed out that team process, which means how to settle team's job tasks, mediated the relationship between team psychological empowerment and team performance [12]. The reason for this conclusion is that team members will plan and organize their own job sequence well, as well as that coordinating self-action to practice better performance strategies in order to meet the team's requirement. The study of virtual teams by Kirkman et al. (2004) also proved the same conclusion. After studying the sales and service teams in high technology organizations, it is concluded that team psychological empowerment will affect customers' satisfaction at first and then come to affect the team performance level. It is expected that high perception of psychological empowerment teams will create higher performance level [8]. Further, Chen's et al. (2007) [14] multi-level study found that leadership climate had a positive impact on team performance through 
the mediation of team psychological empowerment, especially in high interdependent teams, the positive relationship become more significantly.

In the level of organizational performance, team psychological empowerment plays the mediating role as well. The most important mediating variable is customers' satisfaction. When teams have high psychological empowerment , this means that they can examine the reasons of unexpected occurred problems flexibly with autonomy, and they also can respond to the needs and complaints from customers immediately, thereby increasing customers' satisfaction and enhancing organizational performance indirectly [7] [11] [16]. Mathieu et al. (2006) investigated 452 employees and 121 work teams in high-tech organizations and showed that team process played the full mediating role in the relationship that team psychological empowerment affected organizational performance, in other words, team psychological empowerment influenced team process firstly and then influenced the organizational performance [12].

What need to pay attention to is a crucial mediating variable in the relationship between team psychological empowerment and organizational performance-creativity. Innovation is made up of one important part of organizational performance evaluation. Since people who want to innovate need strong intrinsic motivation, so innovation is considered as the bridge in the relationship between team psychological empowerment. Gilson \& Shalley (2004) revealed that when employees realize the value and meaning of their jobs, it is likely that they will increase their creative outcomes. These employees will make more effort to search all kinds of resources to solve problems actively and respond to information promptly after integrating all the methods, resulting in improving employees’ performance directly [23]. Zhang \& Bartol (2010) also found that the higher intrinsic motivation was, the higher creativity level would be, as well as higher organizational operative productivity and organizational profitability. This means that higher team psychological empowerment is beneficial to organizational performance level [4]. According to component model of creativity by Amabile (1996) [2], if individual has the self-determination and control power in his own work, the experiencing of sense of autonomy will motivate employees to adopt more new tentative methods to achieve their job goal. In particular, psychological empowerment shows stronger influence on organizational innovation in team level. Thus, the contribution from team psychological empowerment to team or organizational performance normally transmits by creative factors.

Overall, several empirical studies of a variety of teams and organizations have proved that the mechanism to innovation performance of team psychological empowerment. As the new age of technology reform is coming, the future studies should give priority to the collaborative innovation teams in cross-industries and cross-organizations, and add consequences such as innovation barrier to conduct further examinations.

\section{Conclusions and Research Directions}

The concluded framework can be seen in Figure 1. It is noticeable that the studies on influencing factors and mechanism to performance of team psychological empowerment has achieved abundant outcomes, but there are still quite a few directions for the further explorative studies of team psychological empowerment.

\subsection{To Do Studies of Team Psychological Empowerment in Cross-Boundary Condition}

As far as the concept of team psychological empowerment was proposed, numerous scholars carried out their research in single organization or industry. However, innovation is not limited in isolated company or internal teams, but involves more collaborations in cross-departments, cross-organizations and cross-industries, such as the collaborative innovation. If teams have strong autonomy and freedom, it is no doubt that they will promote the collaborative innovation of production, teaching and research. Future studies should give importance to the relationship between team psychological empowerment and collaborative innovation in cross-boundary condition.

\subsection{Strengthen the Multi-Level Research}

Innovation is a multi-level concept. It can be divided into individual creativity, team innovation and organizational innovation. Prior research mainly focused on single level to study the antecedents and consequences of team psychological empowerment, but future studies should combine team psychological empowerment with individual creativity, team or organizational innovation climate, innovation achievement and so on, exploring their multi-level inter-mechanism profoundly. 


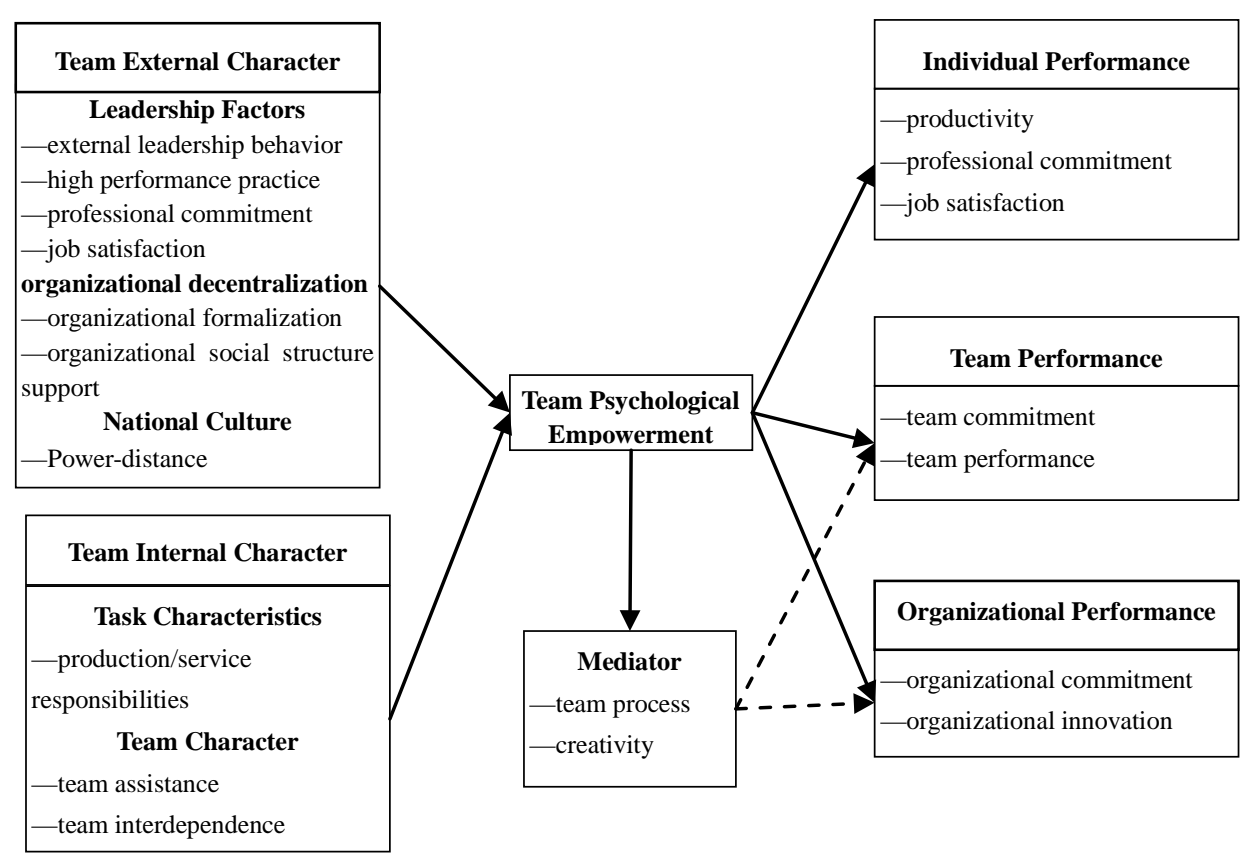

Figure 1. Research framework of team psychological emopwerment. Annotation: the solid lines means it has been proved in empirical studies, while the dash lines mean it only has theoretical induction so far, but still needs more empirical research.

\subsection{Increasing the Consequent Variables of Team Psychological Empowerment}

Existed studies have conducted the theoretical research between team psychological empowerment and innovation performance in many aspects, but it needs more empirical evidence to support the theory. In the meanwhile, scholars should consider some consequent variables such as innovation barrier perception, collaborative innovation and technical innovation. On the other hand, excessive experience of psychological empowerment may create power confliction and fault liability, so the impact of excessive team psychological empowerment toward innovation performance is worthwhile to study as well.

\subsection{Conducting the Studies of Team Psychological Empowerment in Chinese Local Contexts}

Countries that have high collectivism will influence the relationship between team psychological empowerment and innovation performance [24]. In Chinese high collectivism and power-distance cultural contexts, how to implement the perception of psychological empowerment in teams and organizations, especially in those knowledge workers who need high work self-determination and high sense of empowered experience, requires further studies to improve their innovation performance level.

\section{References}

[1] Conger, J.A. and Kanungo, R.N. (1988) The Empowerment Process: Integrating Theory and Practice. Academy of Management Review, 13, 471-482.

[2] Amabile, T.M., Conti, R. and Coon, H. (1996) Assessing the Work Environment for Creativity. Academy of Management Journal, 39, 1154-1184. http://dx.doi.org/10.2307/256995

[3] Thomas, K.W. and Velthouse B.A. (1990) Cognitive Elements of Empowerment: An "Interpretive” Model of Intrinsic Task Motivation. Academy of Management Review, 15, 666-681.

[4] Zhang, X. and Bartol, K.M. (2010) Linking Empowering Leadership and Employee Creativity: The Influence of Psychological Empowerment, Intrinsic Motivation, and Creative Process Engagement. Academy of Management Journal, 53, 107-128. http://dx.doi.org/10.5465/AMJ.2010.48037118

[5] Seibert, S.E., Wang, G. and Courtright, S.H. (2011) Antecedents and Consequences of Psychological and Team Em- 
powerment in Organizations: A Meta-Analytic Review. Journal of Applied Psychology, 96, 981-1003. http://dx.doi.org/10.1037/a0022676

[6] Kirkman, B.L. and Rosen, B. (1997) A Model of Work Team Empowerment. Research in Organizational Change and Development, 10, 131-167.

[7] Kirkman, B.L. and Rosen, B. (1999) Beyond Self-Management: Antecedents and Consequences of Team Empowerment. Academy of Management Journal, 42, 58-74. http://dx.doi.org/10.2307/256874

[8] Kirkman, B.L., Rosen, B. and Tesluk, P.E. (2004) The Impact of Team Empowerment on Virtual Team Performance: The Moderating Role of Face-to-Face Interaction. Academy of Management Journal, 47, 175-192. http://dx.doi.org/10.2307/20159571

[9] Ahearne, M., Mathieu, J. and Rapp, A. (2005) To Empower or Not to Empower Your Sales Force? An Empirical Examination of the Influence of Leadership Empowerment Behavior on Customer Satisfaction and Performance. Journal of Applied Psychology, 90, 945-955. http://dx.doi.org/10.1037/0021-9010.90.5.945

[10] Spreitzer, G.M. (1995) Psychological Empowerment in the Workplace: Dimensions, Measurement, and Validation. Academy of Management Journal, 38, 1442-1465. http://dx.doi.org/10.2307/256865

[11] Hyatt, D.E. and Ruddy, T.M. (1997) An Examination of the Relationship between Work Group Characteristics and Performance: Once More into the Breech. Personnel Psychology, 50, 553-585. http://dx.doi.org/10.1111/j.1744-6570.1997.tb00703.x

[12] Mathieu, J.E., Gilson, L.L. and Ruddy, T.M. (2006) Empowerment and Team Effectiveness: An Empirical Test of an Integrated Model. Journal of Applied Psychology, 91, 97-108. http://dx.doi.org/10.1037/0021-9010.91.1.97

[13] Mills, P.K. and Ungson, G.R. (2003) Reassessing the Limits of Structural Empowerment: Organizational Constitution and Trust as Controls. Academy of Management Review, 28, 143-153.

[14] Chen, G., Kirkman, B.L., Kanfer, R., Allen, D. and Rosen, B. (2007) A Multilevel Study of Leadership, Empowerment, and Performance in Teams. Journal of Applied Psychology, 92, 331-346. http://dx.doi.org/10.1037/0021-9010.92.2.331

[15] Hempel, P.S., Zhang, Z. and Han, Y. (2012) Team Empowerment and the Organizational Context: Decentralization and the Contrasting Effects of Formalization. Journal of Management, 38, 475-501. http://dx.doi.org/10.1177/0149206309342891

[16] Seibert, S.E., Wang, G. and Courtright, S.H. (2011) Antecedents and Consequences of Psychological and Team Empowerment in Organizations: A Meta-Analytic Review. Journal of Applied Psychology, 96, 981-1003. http://dx.doi.org/10.1037/a0022676

[17] Kirkman, B.L. and Shapiro, D.L. (2001) The Impact of Team Members’ Cultural Values on Productivity, Cooperation, and Empowerment in Self-Managing Work Teams. Journal of Cross-Cultural Psychology, 32, 597-617. http://dx.doi.org/10.1177/0022022101032005005

[18] Proenca, E.J. (2007) Team Dynamics and Team Empowerment in Health Care Organizations. Health Care Management Review, 32, 370-378. http://dx.doi.org/10.1097/01.HMR.0000296786.29718.86

[19] Somech, A. (2005) Teachers' Personal and Team Empowerment and Their Relations to Organizational Outcomes: Contradictory or Compatible Constructs? Educational Administration Quarterly, 41, 237-266. http://dx.doi.org/10.1177/0013161X04269592

[20] Zhang, Y. and Begley, T.M. (2011) Power Distance and Its Moderating Impact on Empowerment and Team Participation. The International Journal of Human Resource Management, 22, 3601-3617. http://dx.doi.org/10.1080/09585192.2011.560877

[21] Wang, G.M., Zheng, Q.Q. and Zhao, S.M. (2012) A Study on the Dimension Structure and Measurement of Team Psychological Empowerment. Nankai Business Review, 2, 2-6.

[22] Kuipers, B.S. and Witte, M.C. (2005) The Control Structure of Team-Based Organizations: A Diagnostic Model for Empowerment. Economic and Industrial Democracy, 26, 621-643. http://dx.doi.org/10.1177/0143831X05057504

[23] Gilson, L.L. and Shalley, C.E. (2004) A Little Creativity Goes a Long Way: An Examination of Teams’ Engagement in Creative Processes. Journal of Management, 30, 453-470. http://dx.doi.org/10.1016/j.jm.2003.07.001

[24] Lambe, C.J., Webb, K.L. and Ishida, C. (2009) Self-Managing Selling Teams and Team Performance: The Complementary Roles of Empowerment and Control. Industrial Marketing Management, 38, 5-16. http://dx.doi.org/10.1016/j.indmarman.2007.10.003 
Scientific Research Publishing (SCIRP) is one of the largest Open Access journal publishers. It is currently publishing more than 200 open access, online, peer-reviewed journals covering a wide range of academic disciplines. SCIRP serves the worldwide academic communities and contributes to the progress and application of science with its publication.

Other selected journals from SCIRP are listed as below. Submit your manuscript to us via either submit@scirp.org or Online Submission Portal.
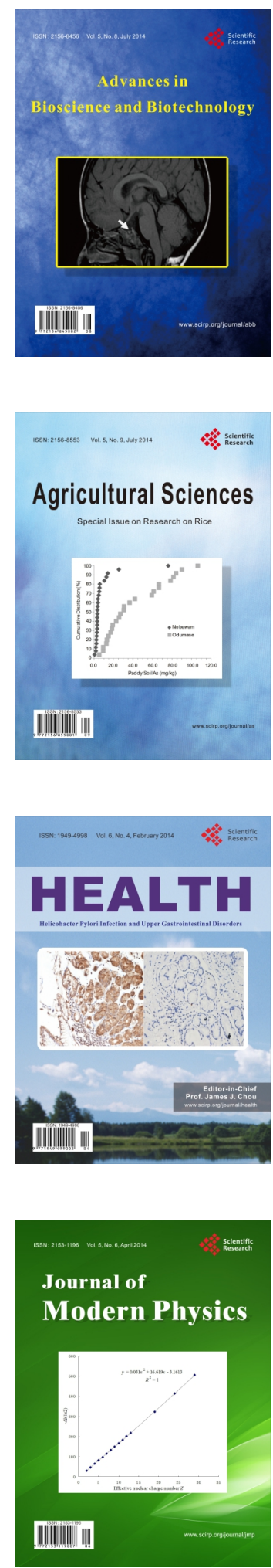
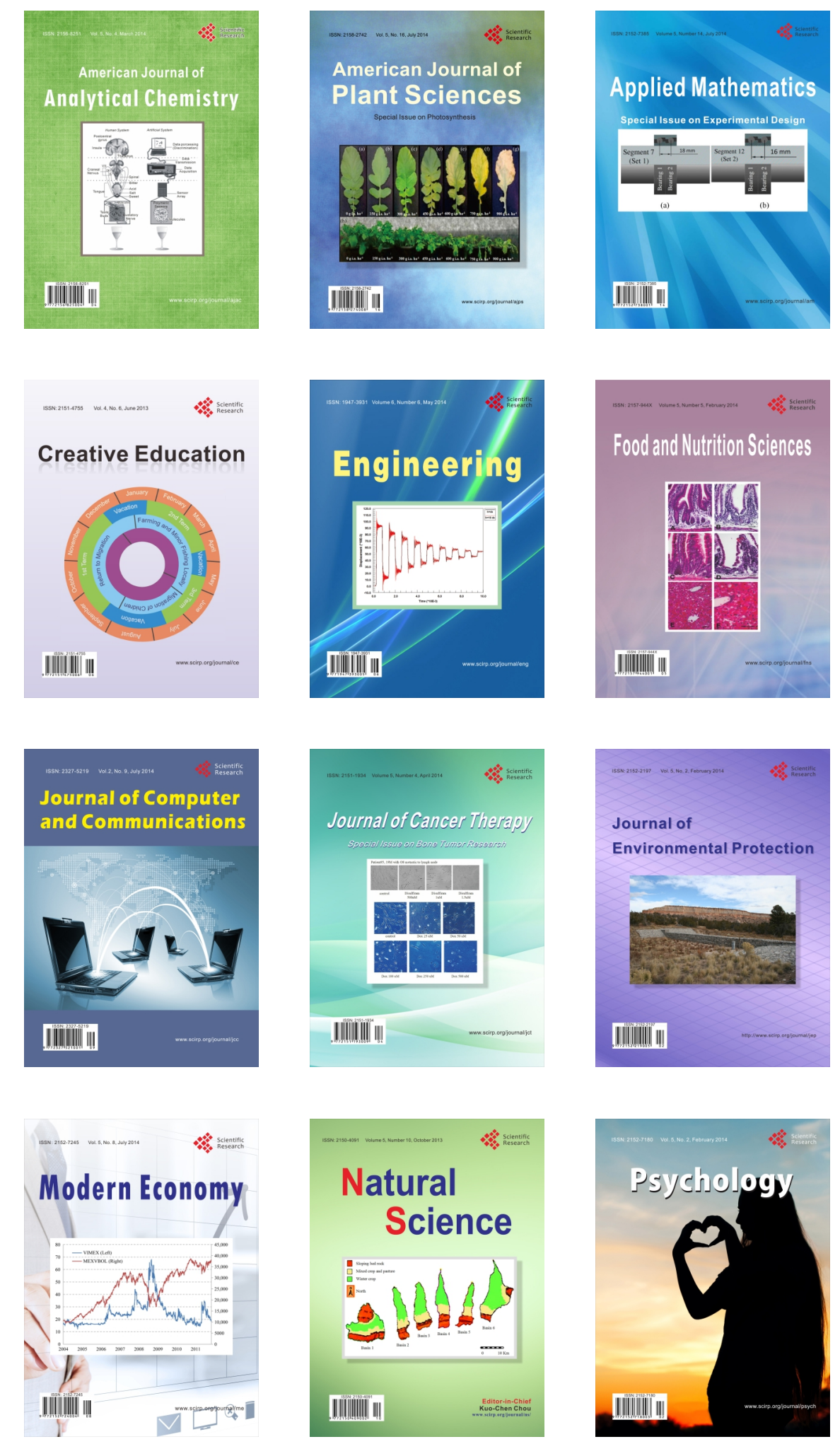